dent, and when questioned on the subject, denies the possibility of its having occurred.

29 th. - Stronger and better; walks about the room, but in a staggering manner, like a drunken man, and with an invincible impulse to move to the left. I discontinued visiting the boy about this period, and did not see him again until some months after the accident; he was then in perfect health, the only trace of the effects of the injury being a slight distortion of the features on the left side of the face. I questioned him about the accident, but he does not retain the slightest recollection of its having occurred; he remembers going out to play, but forgets having drawn the cart. He has returned to school; and it is remarked that he is not less intelligent than he was previous to the occurrence of the accident. What was the exact nature of the injury in this case? Was there a fracture of the base of the skull, or was it merely a case of severe concussion, with laceration of the cavernous sinus? The treatment hardly calls for a remark. I, of course, contented myself with closely watching the natural reparative process, prepared to interfere if the symptoms indicated the necessity for artificial assistance.

I consider this case worthy of being recorded-

1st. As suggestive of the questions placed at the commencement of this report.

2ndly. As a good example of the extreme caution with which medical men should give a prognosis.

3rdly. Because, although isolated cases are of limited value, and insufficient evidence from which to deduce principles of treatment, yet interesting cases are worthy of record, as being the stones with which the future architect may erect a stately edifice.

Shoreditch, London, Feb. 1816.

\section{ON THE "VIS NERVOSA" AND GANGLIONIC INFLUENCE.}

By Cenarles Radclyffe Halu, M.D. Lond., Holmes-Chapel.

IN the report, in The Lancet, of Mr. Rainey's interesting paper on the ganglionic character of the arachnoid membrane of the brain and spinal marrow, the author argues, "that unless the fibres going from the arachnoid to the vessels of the pia mater be organic nerves, the brain, compared with other organs supplied by the sympathetic, would not have a supply of nervous influence proportional to the activity of its formation, and the quantity of blood it receives, and therefore, in this respect, would present an anomaly." (p. 220.) That any influence supplied to less important organs for the regulation of their actions should be withheld from the brain, is not to be expected, but there is nothing improbable in surmising that the mode in which the supply is furnished may be peculiar in an organ to which no other is precisely analogous. The superficial situation of grey matter in some parts of the encephalon, and of white matter in others, has probably an additional purpose to fulfil, besides that of conveniency of packing. The main trunks of the encephalic bloodvessels are not in immediate contact with the grey matter, but the minute twigs from the capillaries of the pia mater are so. The intimate connexion between the pia mater and the grey nervous cells which it invests may be for the purpose of associating the activity of nutritive changes directly and immediately with the activity of nervous action; so that any grey mass, when excited, shall, by the direct operation of its own nervous energy on the minute vessels of its vascular investing membrane, receive an increased supply of arterial blood. I believe that it will ultimately be proved, that the vis nervosa is one and the same kind of force, by whatever nervous centre generated, regulated in its action by the same laws, and producing variety of results solely from variation in the relative arrangement of the nervetubes at their centric and peripheric connexions. In that case, we could scarcely avoid the inference, that the vis generated by the grey cells of the brain must produce a similar influence on the small bloodvessels of the pia mater to that generated by the ganglia and conducted to the capillaries of other organs by the ganglionic nerves. On the nature and extent of this ganglionic influence, it is true, we at present know nothing with certaintv; but, assuming that one effect of the nervous energy on the capillaries is that of causing an afflux of blood to, or a more rapid circulation through, the part, we should have a direct correspondence between cerebral excitement and activity of capillary circulation-a correspondence which, however we may account for it, experience sufficiently declares. It is certainly a pure conjecture, that the vis nervosa can pass from the outer surface of the nerve- cells, but it is a very reasonable one. The microscopic anatomy of the nervous centres is unintelligible without it. If we admit this, with reference to the nerve-cells in the midst of a grey nervous mass, we may admit it of those nearest to the surface of the same mass, amongst which the capillaries more especially ramify.

By these observations, I do not wish to express any doubt of the accuracy of Mr. Rainey's anatomical researches, al though I think that they scarcely suffice to substantiate his conclusions, but merely to show that the very small number of sympathetic nerve-fibres traceable along the arteries of the encephalon may be explained, without admitting the ganglionic character of the arachnoid membrane, or conceding that the brain departs from the analogy of other organs, by assuming that the surface of every grey nervous mass acts immediately on the vessels of the vaseular membrane which covers it, both in the encephalon and in the various ganglia. Perhaps also, this may be a key to one of the offices of the pineal and pituitary bodies.

Holmes-Chapel, Cheshire, Feb. 1846.

\section{ON THE IMMEDIATE CAUSE OF STAMMERING,} AND THE MEANS OF CURE.

By Henry Butrerfield, M.A. Cantab.

Huvivg been engaged for some years in the treatment of stammering and defective speech, $\mathrm{I}$ propose to notice, in TH LANCET, some of the practical results of attentive observation and experiment. U $U^{\prime}$ on the remote cause of stammering I produce no opinion; but I confine myself to the immediate cause. Much has been written upon the question,- "why one person should stammer, and another speak fluently?" But from inattention to an important rule of Sir Isaac Newton, "that no more causes of phenomena are to be admitted than are necessary to explain them," little good has resulted to the public from such inquiries. Would it help us to teach French or Italian, by inquiring into the origin of different languages being spoken? Is not the proper mode that which analyzes the difference between our natural law of speech and the natural law of speech in others? - This point must surely be conceded. Now I have contented myself with this process in cases of stammering and defective speech. The result of continued observation enables me to state,-1. That stammerers try to form a note of sound with a wrong position of the lips or tongue. 2. That the vocal chords of the throat then refuse to act, as the effort is made contrary to the natural law of speech. 3. That bad habits and propensities of the nerves and muscles of speech, producing all the phenomena of stammering, soon follow a few wrong efforts to sound with improper position.

It is important to notice here the difference between a child's speaking with a wrong position of the tongue or lips, and a stammerer's trying to speak so. The child, very quietly and unconscionsly, combines the rowel of the syllable, whether the consonant position has been right or not,- thus, it says $t$ for $k$, in the word key; $d$ for $g$, in the rord game. But the stammerer does not combine the vowel with the consonant; he will produce numerous notes of sound, but no vowel will follow in combination, as in the case of the child's prattle; until, with great effort, he has, by chance, approximated to right position, or until he has attained it: then, out bursts the vowel of the syllable, and several syllables or words continuously follow.

The practice or experiment connected with these observations is extremely simple, although it must be specially adapted to every individual case.

I endeavour to produce the first intention of cure by alienating from the bad habits and propensities of the nerves and muscles of speech. This is done by my teaching the method of respiration used by the best professional singers and speakers; and by the use of an alphabet formed to act upon the attention of the mind and the vocal chords of the throat at the same instant.

The subsequent training is derived from the nature of accent and from the grammatical combination of words in a sentence. I teach the stammerer to think and speak his sentences in grammatical parts, and show him that good accentual speaking produces the greatest distinctness and force upon the ear with the greatest ease to the throat, lungs, and organs of respiration. And with this method carried on to the practice of extempore narration, I find that even those who " creep unwillingly to school," and puzzle their tutors, by stammering wilfully with the mouth, to hide the stammering of the mind, 
can be made with certainty to read and speak properly when they please.

My engagement for some years as extra master, at Eton, for the treatment of stammering and defective speech, has enabled me to pursue my course of observation and experiment with the greatest advantage; and several eminent surgeons have recommended me to extend my treatment of this calamity, in conjunction with their medical or surgical treatment when required.

Sackville-street, Piccadilly, Feb. 1846

${ }_{*}^{*}$ The insertion of this brief article demands from us the remark, that the treatment and cure of stammering belong to the profession of medicine.-ED. $\mathrm{L}$.

\section{SCARLATINA IN THE BAHAMAS.}

SUPPOSED LATENCY OF THE DISEASE FOR ELEVEN WEEKS.

By Frederick Doxcome, Esq., M.D., Nassau, Bahamas.

THE following circumstances will probably be deemed of sufficient importance and interest to merit a place in THE LANCET, as illustrating the extent to which the latent period of scarlatina may be protracted. In this colony, the disease in question is not known to have occurred for the last forty years.

During the past summer, this malady had prevailed in some of the American cities, to an alarming and fatal extent. Amongst the sufferers was a family belonging to this place, then on a visit to Philadelphia. One young man was cut off by it, and of the four daughters, three took the disease. The youngest, aged about six years, had been secluded from the others for six weeks in a separate house, and escaped the fever. Every precaution was taken to prevent fomites. Three weeks were spent in America after the reunion of the family, and after a fortnight's passage, they arrived at this place on October 13th. Upon the 20th of December the youngest girl was attacked with " scarlatina anginosa." This case was seen by $D_{r}$. Chipman and myself, and was succeeded by some of the usual sequela, as otorihœa, wry neck, œdema, and albuminous urine, the latter being marked by inflammatory symptoms.

In this history, fourteen weeks elapsed between the time our little patient was restored to the company of her convalescent sisters, and the subsequent date of the fever breaking out in her. At any rate, we have an interval of eleven weeks between the period of embarkation from America and the breaking out of the disease in this place; so that, for at least eleven weeks, and probably longer, the infection must have remained latent in her system. Upon minute inquiry, there does not appear any reason to suppose that the malady was introduced into this place by fomites. This case did well, and the fever has not as yet spread.

Nassau, Bahamas, Jan, 1846.

\section{ROYAL MEDICAL AND CHIRURGICAL SOCIETY.}

MARCH 10.-DR. BABINGTON, VICE-PRESIDENT, IN THE CHATR.

AN ACCOUNT OF A CASE OF PARTIAL DOUBLE MONSTROSITY (ISCHIOPAGE SYMELIEN OF GEOFFROY SAIN' HILAIRE, UETERADELPHIA of vrolic.)-By Wiluiam Acton, Esq. Surgeon to the Islington Dispensary.

The subject of the monstrosity is a healthy male child, a native of Portugal, six months old, brought to this country for exhibition. The parents, and a brother and a sister, exhibited no peculiarity of any kind. The infant is lively and good-looking, and well proportioned both in the upper and lower extremities. The peculiarities are confined to the parts below the umbilicus. To the right and left of the mesial line are two distinct penes, each as large as the penis of a child of six months. Water is passed from both organs at the same moment. Each penis is provided with a scrotum, the outer half of each scrotum containing one testicle; the inner half of the scrotum is far removed from the outer, and the two inner halves appear like another scrotum between the two penes. Between and behind the legs of the child there is another limb, or rather, two lower extremities, united together in their whole length. The upper part of this compound limb is connected to the rami of the pubis by a short narrow stem. Immediately beyond this stem, and concealing it, the compound limb assumes a size as large as the com- bined natural thighs. The leg is of comparatively small size; though larger than either of the healthy legs, and terminates in a double foot, with the sole turned forwards, and provided with ten toes, of which the two outer on each side are webbed. The anus is in its usual situation. Viewed posteriorly, the compound limb assumes a roundness and fulness equal to the buttocks of a young child, and a slight depression is observed, as if for the anus. The compound limb is motionless; the upper portion alone appears endowed with sensibility, and its vitality seems low.

The author states that he has consulted most of the original works referred to by authors who have described this species of monstrosity, but he has been unable to find exactly analogous cases, or any description or plate of two penes on one body, as in the case before the Society. He believes that this instance of double penis does not depend upon a division of one organ. The distance at which they are placed one from the other, and the existence of two canals, by which urine is passed at the same moment, renders this little probable.

With reference to the question of removal of this compound $\operatorname{limb}$, the author considers that every circumstance is in favour of an operation. He notices the health of the child, the narrowness of the medium of communication, which contains probably no important part, but especially the low vitality of the limb, as the history of partial double monstrosities shows that any, however slight, scratch or contusion heals slowly, and generally ends, at first in the death of the part, and subsequently of the child. If the infant escapes this source of danger, its system is found incapable of supporting this additional limb, and the child perishes from debility. He thinks, therefore, that an operation will be necessary to give the child a chance of arriving at puberty, and that, in the absence of any one counter-indication, the sooner this is performed the better for the security of the child.

The parents brought the subject of this curious monstrosity to the rooms of the Society, where it was examined by the fellows present previous to the meeting.

Dr. Bubivaron observed, that in Mr. Acton's paper, the only point for discussion seemed to be the propriety of an operation.

Mr. LLoxp did not agree with the author of the paper with respect to the propriety of removing the supernumerary limb in this case. Recollecting how small a quantity of blood might destroy so young a child, and looking at the size of the limb, which, no doubt, was supplied by considerable vessels, he could not see how hæmorrhage could be prevented from going on to a fatal termination. Mr. Lloyd then alluded to the danger of hæmorrhage from the removal of nævi; he thought that in this case peril would also arise from the division of a great number of vessels at once.

Mr. Acton was afraid that $M r$. Lloyd had had an imperfect view of the child, and had not distinctly heard the paper; he should therefore refer to some points, in order to show the facilities which existed for the operation. The toes of the lower compound limb were blue, showing the languor of the circulation in them, notwithstanding all the precautions taken by the parents. It was found, in all similar cases, that very slight abrasion resulted in ulceration difficult of cure, and frequently terminating in death of the part, and sometimes of the child. Even if the infant were free from this contingency, the powers of one individual were insufficient to nourish the additional limb, and atony ensued. He was still of opinion, after careful and repeated examinations, that an operation should and could be performed. The connexion between the two limbs consisted of a stem, about as thick as a finger, at the rami of the pubes. No pulsation of large vessels was to be detected, nor any vital organ which might be injured by the operation. Hrmorrhage, from the position and small size of the stem, might be readily controlled. This case offered more chances of success, and showed the greater necessity of an operation than any on record.

ACCOUNT OF A CASR IN WHICH THE CORPLS CALLOSUM, SEPTUM LUCIDUM, AND FORNIX, WERE IMPERFECTLX FORMRD.-BY JAmes PAGET, Esq., Lecturer on General and Morbid Anatomy, and Warden of St. Bartholomew's Hospital.

The case here related is that of a servant-girl who died with pericarditis. She had displayed during life nothing very remarkable in her mental condition. She was of good moral character, trustworthy, and fully competent to all the duties of her station. She had a good verbal memory, and as much knowledge as is commonly acquired in such slender education as she had received. She was good. tempered, happy, and very heedless. Her mother was insane 